\title{
Contrast Enhanced X-ray
}

National Cancer Institute

\section{Source}

National Cancer Institute. Contrast Enhanced X-ray. NCI Thesaurus. Code C154783.

An $\mathrm{x}$-ray technique that incorporates the administration of an iodinated contrast ag ent to enhance lesions that are not visible on standard $x$-rays. 